\title{
Optogenetic Stimulation of Accumbens Shell or Shell Projections to Lateral Hypothalamus Produce Differential Effects on the Motivation for Cocaine
}

\author{
Erin B. Larson, Anne M. Wissman, Amy L. Loriaux, Saïd Kourrich, and David W. Self \\ Department of Psychiatry, University of Texas Southwestern Medical Center, Dallas, Texas 75390
}

\begin{abstract}
Previous studies suggest that pharmacological or molecular activation of the nucleus accumbens shell (AcbSh) facilitates extinction of cocaine-seeking behavior. However, overexpression of CREB, which increases excitability of AcbSh neurons, enhances cocaine-seeking behavior while producing depression-like behavior in tests of mood. These discrepancies may reflect activity in differential AcbSh outputs, including those to the lateral hypothalamus (LH), a target region known to influence addictive behavior and mood. Presently, it is unknown whether there is a causal link between altered activity in the AcbSh-LH pathway and changes in the motivation for cocaine. In this study, we used an optogenetics approach to either globally stimulate AcbSh neurons or to selectively stimulate AcbSh terminal projections in the $\mathrm{LH}$, in rats self-administering cocaine. We found that stimulation of the AcbSh-LH pathway enhanced the motivation to self-administer cocaine in progressive ratio testing, and led to long-lasting facilitation of cocaine-seeking behavior during extinction tests conducted after withdrawal from cocaine self-administration. In contrast, global AcbSh stimulation reduced extinction responding. We compared these opposing motivational effects with effects on mood using the forced swim test, where both global AcbSh neuron and selective AcbSh-LH terminal stimulation facilitated depression-like behavioral despair. Together, these findings suggest that the AcbSh neurons convey complex, pathway-specific modulation of addiction and depression-like behavior, and that these motivation and mood phenomenon are dissociable.
\end{abstract}

Key words: cocaine; mood; motivation; optogenetics; self-administration

\section{Introduction}

Addiction is a complex behavioral disorder that involves compulsive motivation for drugs despite adverse consequences, including negative affective states in withdrawal (Markou and Koob, 1991; Frankowska et al., 2010). These motivational and affective disturbances are thought to reflect drug-induced neuroadaptations in brain reward circuits following chronic drug use, and changes in reward circuit function have been implicated in other mood-related disorders including depression (Berridge and Kringelbach, 2013). Neuroadaptations in the nucleus accumbens (Acb) are of particular relevance to both addiction and moodrelated disorders, given its role as a limbic-motor interface and its ability to modulate both rewarding and aversive behavior (Carlezon and Thomas, 2009; Eshel and Roiser, 2010; Kravitz and Kreitzer, 2012). For example, chronic drug use and withdrawal enhances the function of the CAMP response element binding protein (CREB; Self and Nestler, 1998). In turn, increased CREB

\footnotetext{
Received April 14, 2014; revised Jan. 13, 2015; accepted Jan. 15, 2015.

Author contributions: E.B.L. and D.W.S. designed research; E.B.L., A.M.W., A.L.L., and S.K. performed research; E.B.L. analyzed data; E.B.L., A.M.W., and D.W.S. wrote the paper.

This work was supported by NIDA Grants DA010460 and DA026482. We thank April Becker, Steven Lind, and Lauren Peca for technical assistance scoring the forced swim test.

The authors declare no competing financial interests.

Correspondence should be addressed to David W. Self, Department of Psychiatry, University of Texas Southwestern, 5323 Harry Hines Boulevard, Dallas, TX 75390-9070. E-mail: david.self@utsouthwestern.edu.

DOI:10.1523/JNEUROSCI.1524-14.2015

Copyright $\odot 2015$ the authors $\quad 0270-6474 / 15 / 353537-07 \$ 15.00 / 0$
}

activity in the Acb shell region (AcbSh) enhances the motivation for cocaine in self-administering animals (Larson et al., 2011), but can also facilitate negative affective states (Pliakas et al., 2001; Muschamp et al., 2011). Elevated CREB activity also enhances the intrinsic excitability of AcbSh neurons (Dong et al., 2006), an effect that may encode negative affective and aversive behavioral states (Carlezon and Thomas, 2009). Together, these findings suggest that CREB-induced increases in excitability of AcbSh neurons could lead to enhanced motivation for cocaine by facilitation of negative reinforcement processes. Conversely, these effects on motivation and mood may result from activation of different AcbSh outputs to the ventral tegmental area (VTA), ventral pallidum (VP), and/or lateral hypothalamus (LH).

The unique GABAergic projection from the AcbSh to the $\mathrm{LH}$ (AcbSh-LH) may be of particular relevance for modulation of motivation and mood by CREB and chronic cocaine use. Both the AcbSh and LH mediate food-motivated behavior (Kelley et al., 2005), and changes in activity within the AcbSh can alter activity of neuronal targets including orexin neurons in the LH (Stratford and Kelley, 1999; Millan et al., 2010). Indeed, LH orexin neurons play a critical role in both addictive and depressive-like states (Aston-Jones et al., 2010; Berridge et al., 2010; Sharf et al., 2010; Marchant et al., 2012; Nocjar et al., 2012). Given these findings, we hypothesized that increased activity in AcbSh-LH projecting neurons would enhance the motivation for cocaine in self-administering rats, but also induce behavioral de- 
spair in forced swim tests, similar to the effects of global increases in CREB activity in AcbSh neurons. We used an optogenetic approach to selectively stimulate of AcbSh-LH terminals, and compared the behavioral effects with global optogenetic stimulation of AcbSh neurons.

\section{Materials and Methods}

Subjects. Adult male Sprague-Dawley rats were housed and habituated as previously described (Larson et al., 2011). All experimental protocols were approved by the Institutional Animal Care and Use Committee (University of Texas Southwestern Medical Center).

Food training. Animals were trained to lever-press for food pellets on a fixed ratio 1 (FR1) reinforcement schedule as previously described (Larson et al., 2011).

Surgical procedures. Surgery occurred under ketamine/xylazine $(100 / 10 \mathrm{mg} / \mathrm{kg}$, i.p.) anesthesia. Viral injection parameters were initially validated by injecting the retrograde tracer cholera toxin $\mathrm{B}$ (CtB) into the $\mathrm{LH}$ ( $\mathrm{AP}-2.12 \mathrm{~mm}, \mathrm{ML} \pm 2.0 \mathrm{~mm},-8.2 \mathrm{~mm}$ ventral to dura; Paxinos and Watson, 1998; Stratford and Kelley, 1999). For behavioral experiments, animals were given bilateral intracranial infusions of either AAV2-hSyn-hChR2(H134R)-EYFP or AAV2-hSyn-EYFP control virus $\left(1.0 \mu \mathrm{l} / \mathrm{side} ; \sim 1 \times 10^{12}\right.$ viral particles $/ \mathrm{ml}$; University of North Carolina Gene Therapy Center). Viral infusions were delivered into the AcbSh (AP $+1.7 \mathrm{~mm}, \mathrm{ML} \pm 0.8 \mathrm{~mm},-6.7 \mathrm{~mm}$ ventral from dura) at a rate of 0.1 $\mu \mathrm{l} / \mathrm{min}$, with a $5 \mathrm{~min}$ postinfusion hold to allow for viral particle diffusion before needle removal. Bilateral optic cannulae ( $300 \mu \mathrm{m}$ core; Doric Lenses) were then implanted $\sim 0.5 \mathrm{~mm}$ dorsal to the AcbSh or $\mathrm{LH}$, and were secured to the skull using machine screws and dental acrylic (Stoelting). Animals were treated postoperatively with penicillin (60,000 IU/0.2 $\mathrm{ml}$, s.c.) and ketofen $(5 \mathrm{mg} / \mathrm{kg}$, s.c., $2 \times / \mathrm{d}$ for $3 \mathrm{~d}$ ) and recovered for $\geq 3$ weeks before behavioral testing to allow for viral transport throughout infected neurons. Animals that underwent cocaine self-administration procedures were additionally implanted with chronic, indwelling SILASTIC catheters as previously described (Edwards et al., 2007; Larson et al., 2011).

Optogenetic stimulation. Bilateral optical stimulation of cell bodies in the AcbSh (global stimulation condition) or AcbSh nerve terminals in the LH (selective AcbSh-LH stimulation condition) was performed using a $200 \mathrm{~mW}, 473 \mathrm{~nm}$ diode-pumped solid-state laser (DPSS Lasers). Light intensity from the bilateral fibers was adjusted to $\sim 15-20 \mathrm{~mW}$ intensity at each tip before stimulation, which yielded sufficient irradiance at the target tissue $\left(\sim 5-8 \mathrm{~mW} / \mathrm{mm}^{2}\right)$ to activate the ChR2 proteins. Optical stimulation occurred immediately before progressive ratio (Days 1 and 2) or forced swim (Day 2) testing, and was given over $30 \mathrm{~min}$ at a rate of $20 \mathrm{~Hz}$ for $10 \mathrm{~s} / \mathrm{min}$ (200 pulses/min, $10 \mathrm{~ms}$ pulse duration). A similar stimulation protocol has been shown to evoke reliable action potential firing of LH neurons in vivo (Adamantidis et al., 2007). Both control (AAV-EYFP) and experimental (AAV-ChR2-EYFP) animals received optical stimulation to control for potential indirect effects of exposure to the laser light. This "pretreatment" method was used to enhance basal activity states without interfering with inherent neuronal activation during behavioral testing for cocaine self-administration or forced swim. It also provided consistent stimulation parameters and duration for both self-administration and forced swim tests, ensured a full range of horizontal and vertical motion during the behavioral tests (as animals were not tethered to the optic cables).

Cocaine self-administration. Animals were given access to cocaine (0.5 $\mathrm{mg} / \mathrm{kg} /$ infusion, i.v.) on a FR1 reinforcement schedule in daily $4 \mathrm{~h}$ sessions conducted $5 \mathrm{~d}$ /week for a total of 3 weeks. Only animals that showed stable intake patterns (Edwards et al., 2007; Larson et al., 2011) were used in subsequent progressive ratio (PR) testing. PR sessions occurred over 2 consecutive days ( $5 \mathrm{~h} / \mathrm{d}, 1.0 \mathrm{mg} / \mathrm{kg} / \mathrm{infusion}$, i.v.), and breakpoints were assessed as previously described (Richardson and Roberts, 1996; Larson et al., 2011). After PR testing, animals underwent forced withdrawal from cocaine access, and remained in their home cage for 1 week. Animals were then returned to the self-administration context under extinction conditions where lever-press behavior was recorded, but was without consequence. Extinction of cocaine-seeking behavior in the self-administration context was examined for $4 \mathrm{~h} / \mathrm{d}$ over $6 \mathrm{~d}$.
Forced swim test. A standard $2 \mathrm{~d}$ forced swim procedure (Castagné et al., 2011) was used to measure depression-like behavioral despair after optogenetic stimulation. On Day 1, rats were placed into a cylinder of water $\left(28 \pm 2^{\circ} \mathrm{C}\right.$, diameter: $31 \mathrm{~cm}$, depth: $46 \mathrm{~cm}$, water depth $\left.30 \mathrm{~cm}\right)$ for $15 \mathrm{~min}$ of forced swim stress exposure. On Day 2, animals received 30 min of optogenetic stimulation and were immediately placed into the water for a $5 \mathrm{~min}$ forced swim test. Animals were perfused and brains were taken for immunohistochemistry $90 \mathrm{~min}$ after optogenetic stimulation. The latency to first passive coping behavior (first incidence of floating/immobility lasting $>1$ s) and total time spent immobile was scored by two individuals blind to treatment conditions.

Locomotor activity. Animals were given $30 \mathrm{~min}$ of optogenetic stimulation and were immediately placed into a circular locomotor apparatus (Edwards et al., 2007) where activity levels were measured over $30 \mathrm{~min}$.

Histology and immunohistochemistry. Immunohistochemistry procedures (Larson et al., 2011) were used to validate AcbSh areas that projected to the LH (CtB experiment), to assess proper placement of optic cannula in the AcbSh (global stimulation condition) or LH (targetspecific stimulation condition), and to examine stimulation-related changes in neuronal activity. For the CtB experiment, CtB-injected animals were perfused $7 \mathrm{~d}$ after $\mathrm{CtB}$ injections into the $\mathrm{LH}$, and an antibody directed against CtB (1:100; List Biological Laboratories) was used to localize AcbSh neurons that project into the LH. For cannula placement, animals used for behavioral experiments were perfused at least 3 weeks after viral injections, and localization of injected AAV-ChR2-EYFP and AAV-EYFP viruses was done using a GFP antibody (1:4000, Aves Labs). For stimulation-related changes in neuronal activity, a cFos antibody (1:500, Santa Cruz Biotechnology) was used to examine cFos immunoreactivity $90 \mathrm{~min}$ after optogenetic stimulation and forced swim tests. This approach maximized our ability to detect optogenetic-mediated reductions in LH cFos activity, which is typically low in unstressed animals (Martinez et al., 1998). Counts were done in an area directly under the optic cannula track (AcbSh: $\sim+1.7 \mathrm{~mm}, \mathrm{LH}: \sim-2.12 \mathrm{~mm}$ relative to bregma), and care was taken to examine slices that showed similar levels of viral expression. Double-labeling for cFos in orexin-positive neurons was done using an orexin antibody (1:100, Millipore), and cFos/orexin colocalization was examined at an area slightly posterior to the site of the optic cannula ( $\sim 2.6 \mathrm{~mm}$ posterior to bregma). This approach was chosen given the potential monosynaptic and/or disynaptic nature of AcbSh projections to orexin neurons in the LH (Zheng et al., 2003; Sano and Yokoi, 2007). Images $(20 \times)$ taken from two adjacent slices from each region of interest were used for quantification of $\mathrm{cFos}$ and $\mathrm{cFox} /$ orexin colocalization. Given the transient nature of cFos induction (Morgan and Curran, 1989) and the extended nature of our self-administration testing procedures, cFos levels were only examined after optogenetic stimulation and forced swim testing.

Electrophysiology. Bilateral infusions of AAV2-hSyn-hChR2(H134R) into the AcbSh were performed as described above, without the optic cannula implant. Animals were given $4-5$ weeks to recover and express ChR2 in axon terminals before brains were taken and prepared for slice electrophysiology. For AcbSh recordings, animals were anesthetized with chloral hydrate $(400 \mathrm{mg} / \mathrm{kg}$, i.p.) and perfused with oxygenated cold sucrose ACSF (in mM: $\mathrm{NaCl} 75$, sucrose $75, \mathrm{KCl} 2, \mathrm{NaHCO} 325$, glucose $15, \mathrm{NaH}_{2} \mathrm{PO}_{4} 1.25$, sodium pyruvate 2.4 , ascorbic acid $1.3, \mathrm{MgSO}_{4} 3$, $\mathrm{CaCl} 20.5$, kynurenic acid 2). Brains were extracted, blocked, and $300 \mu \mathrm{m}$ coronal slices were collected in the cold sucrose ACSF solution on a Leica 2100 VS microtome. Slices were then held at room temperature in regular ACSF (in mu: $\mathrm{NaCl} 119, \mathrm{KCl} 2.5, \mathrm{NaHCO} 326.2$, glucose 11, $\mathrm{NaH}_{2} \mathrm{PO}_{4} 1$, $\left.\mathrm{MgSO}_{4} 1.3, \mathrm{CaCl} 22.5\right)$ until transfer to the rig for recording in regular ACSF at $32^{\circ} \mathrm{C}$. For LH recordings, animals were anesthetized with chloral hydrate, rapidly decapitated, and $250 \mu \mathrm{m}$ parasagittal slices were collected in cold NMDG-ACSF (containing the following in mM: NMDG 92, HEPES 20, $\mathrm{KCl} 2.5, \mathrm{NaHCO}_{3} 30$, glucose 25, $\mathrm{NaH}_{2} \mathrm{PO}_{4}-2 \mathrm{H}_{2} \mathrm{O}$ 1.2, $\mathrm{Na}$-ascorbate 5, Na-pyruvate 3, thiourea $2, \mathrm{HCl} \sim 80, \mathrm{MgSO}_{4} 10, \mathrm{CaCl}_{2}$ 0.5 ). Slices were kept at room temperature in HEPES-ACSF (containing the following in mM: $\mathrm{NaCl} 92$, HEPES $20, \mathrm{KCl} 2.5, \mathrm{NaHCO}_{3} 30$, glucose 25, $\mathrm{NaH}_{2} \mathrm{PO}_{4}-2 \mathrm{H}_{2} \mathrm{O} 1.2, \mathrm{Na}$-ascorbate 5, Na-pyruvate 3, thiourea 2, $\mathrm{NaOH} \sim 7, \mathrm{MgSO}_{4} 1, \mathrm{CaCl}_{2} 2$ ) until transfer to the rig for recording in regular ACSF at $32{ }^{\circ} \mathrm{C}$. Kynurenic acid $(2 \mathrm{~mm})$ was added to the bath 
A

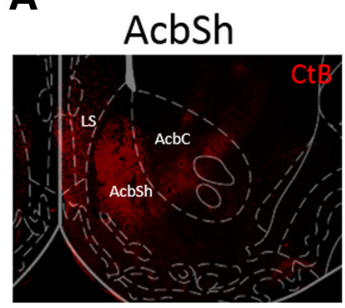

B
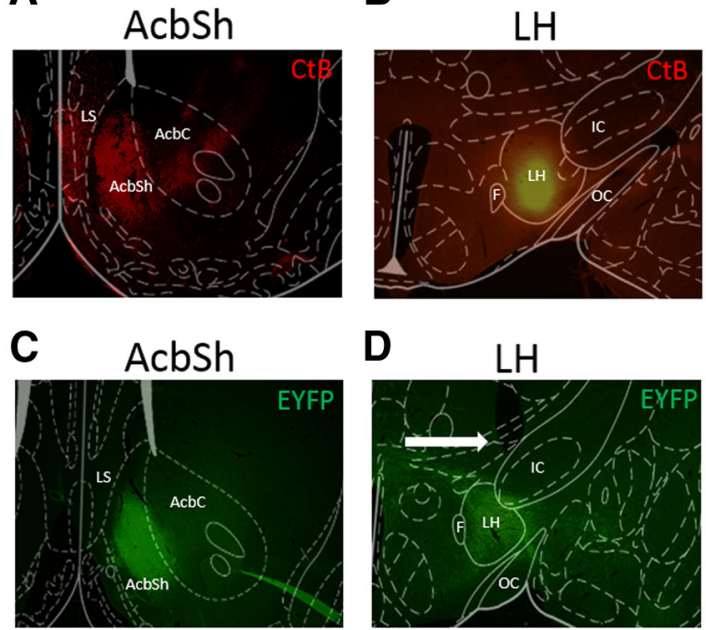

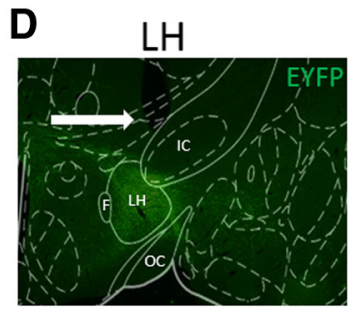

E

E Global AcbSh groups Virus AcbSh Optic cannula AcbSh

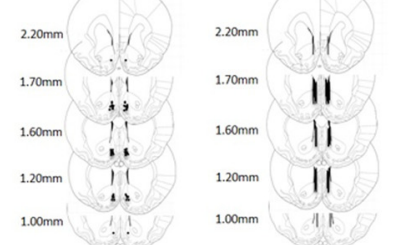

F Selective AcbSh-LH groups Virus AcbSh Optic cannula LH

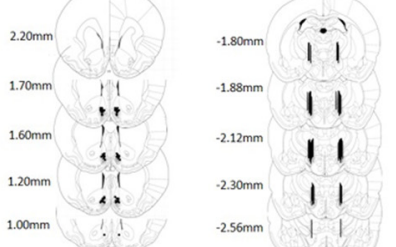

Figure 1. Validation of injection parameters. $A, C+B+$ cell bodies in the $A c b S h$ and $L S$ regions after $(B) C+B$ injection into the $L H$. C, Acute AAV infusions are restricted to the AcbSh region, without diffusion into the adjacent LS. D, Optic cannula implanted just dorsal to AcbSh terminal regions in the LH. $E$, $F$, Histology panels showing regions of AAV viral infusions in the AcbSh (left) and optic cannula placement (right) for global AcbSh $(\boldsymbol{E})$ and selective AcbSh-LH $(\boldsymbol{F})$ stimulation groups. Images shown at $4 \times$ magnification.

A

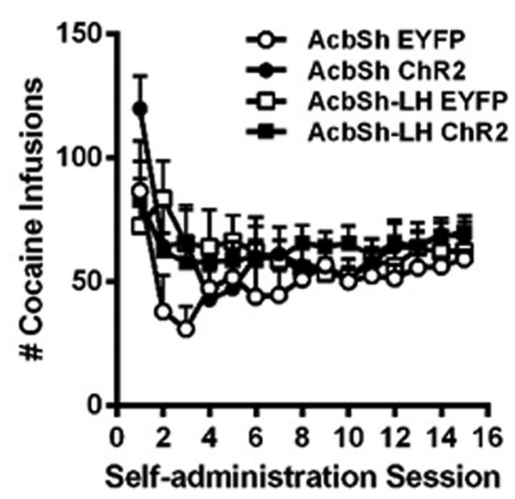

C

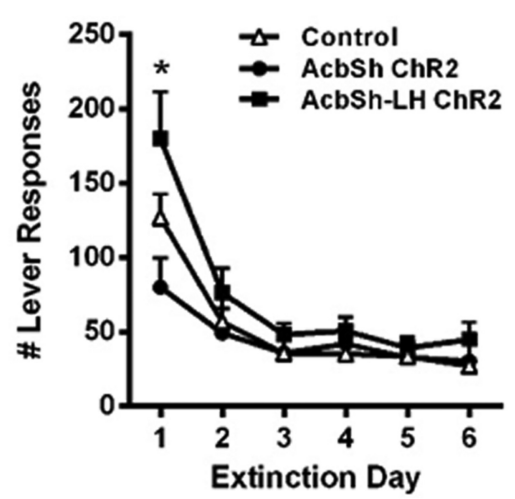

B
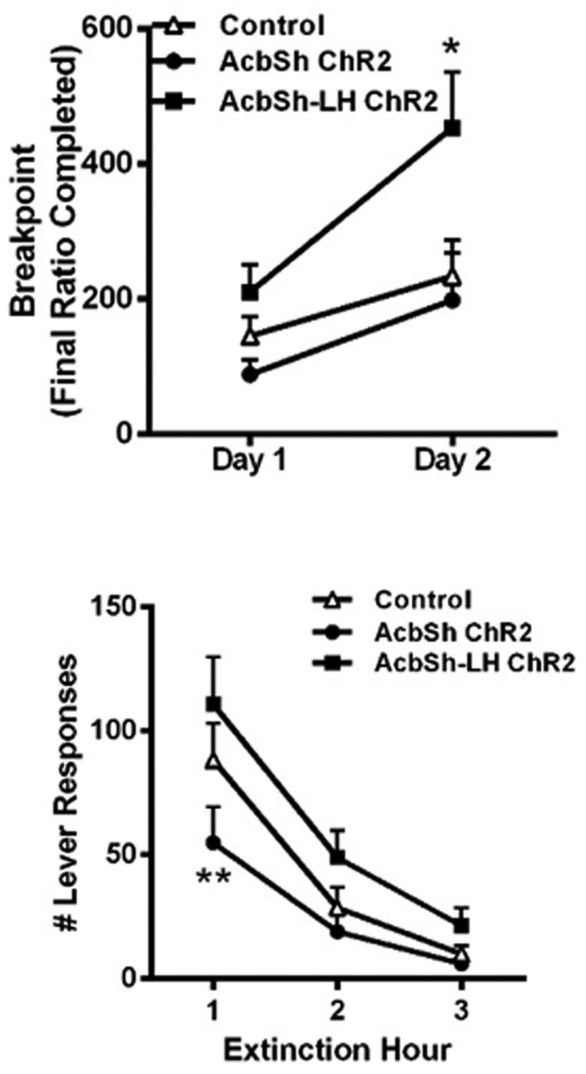

Figure 2. Differential effects of global AcbSh and selective AcbSh-LH stimulation on the motivation for cocaine and cocaine-seeking behavior after withdrawal from cocaine self-administration. $\boldsymbol{A}$, Cocaine self-administration $(0.5 \mathrm{mg} / \mathrm{kg}$, FR1) before optogenetic stimulation. $\boldsymbol{B}$, Selective AcbSh-LH terminal stimulation increased breakpoints achieved during the $2 \mathrm{~d}$ progressive ratio testing. $\mathbf{C}$, Selective AcbSh-LH terminal stimulation increased, whereas global AcbSh neuron stimulation tended to reduce, context-induced cocaine-seeking behavior on Day 1 of extinction testing. D, Global AcbSh neuron stimulation reduced initial (hour 1) cocaine-seeking behavior on Day 1 of extinction, whereas selective AcbSh-LH terminal stimulation produced mild enhancement in responding across the session; ${ }^{*} p<0.05,{ }^{* *} p<0.01$ versus control, $n=8-11 /$ group

upon patching a cell in the LH to block glutamate receptors, and whole-cell current-clamp recordings were performed with electrodes (3-5 $\mathrm{M} \Omega$ ) containing the following (in $\mathrm{mm}$ ): $120 \mathrm{~K}$-gluconate, $20 \mathrm{KCl}, 10 \mathrm{HEPES}, 0.2$ EGTA, $2 \mathrm{MgCl}_{2}, 4 \mathrm{Mg}$-ATP, and $0.3 \mathrm{Na}$-GTP, $\mathrm{pH} 7.20-7.25$. Data were filtered at $5 \mathrm{kHz}$, digitized at $10 \mathrm{kHz}$, and collected and analyzed using Clampex 10.3 software (Clampex 10.3.0.2, Molecular Devices). Membrane potentials in voltage-clamp were maintained at $-80 \mathrm{mV}$ in the AcbSh and $-60 \mathrm{mV}$ in the $\mathrm{LH}$, series resistances (10-18 M $\Omega$ ) and input resistances were monitored on-line with a $-40 \mathrm{pA}$ current injection $(150 \mathrm{~ms})$ given at the beginning of each trace. Recordings were also performed in current-clamp, and the cell type (i.e., medium spiny neuron vs interneuron) was determined based on the firing pattern in response to a series of current injections $(-80$ to $+440 \mathrm{pA}$; $700 \mathrm{~ms}$; Belleau and Warren, 2000). Light stimulation was induced with a $50 \mathrm{~mW}, 473 \mathrm{~nm}$ diode-pumped solid-state laser triggered by a Master8 stimulus generator. A bare optic fiber delivered optogenetic stimulation (1$2.5 \mathrm{~mW}$ ) and was positioned to optimize responses to a series of $2 \mathrm{~Hz}$ pulses. When responses to light pulses stabilized, the neuron received the same stimulation parameters used for in vivo treatments (200 pulses of $10 \mathrm{~ms}$ at $20 \mathrm{~Hz}$ ).

Statistics. All data are expressed as mean \pm SEM. Analysis was done with Prism GraphPad software. Two-way repeated-measures ANOVAs were used to examine self-administered cocaine infusions, PR breakpoints, and lever responding during extinction. Linear regression analysis was used to assess correlations between latency and total immobility measures during forced swim testing. One-way ANOVAs were used to examine immobility during forced swim testing, cFos immunoreactivity, and cFos/orexin colocalization. Significant main effects $(p<0.05)$ were followed by NewmanKeuls post hoc tests to examine group effects in relation to controls.

\section{Results}

Targeting AcbSh-LH neuronal projections

Validation of viral injection parameters are represented in Figure 1. Initial retrograde tracing experiments revealed $\mathrm{CtB}+$ cell bodies in both the anterior AcbSh and lateral septal regions (LS; Fig. 1A) after $\mathrm{CtB}$ injection into the LH (Fig. 1B). AAV viruses were infused directly into the AcbSh subregion in a manner that prevented viral spread into the adjacent LS (Fig. 1C). Optic cannula were implanted $\sim 0.5 \mathrm{~mm}$ above the appropriate $\mathrm{LH}$ region (Fig. 1D), to maximally stimulate AcbSh-LH nerve terminals in the selective-stimulation groups. Only animals that had correct placement of both the AAV virus and optic cannula were used for behavioral and immunohistochemical analysis (Fig. 1 
A

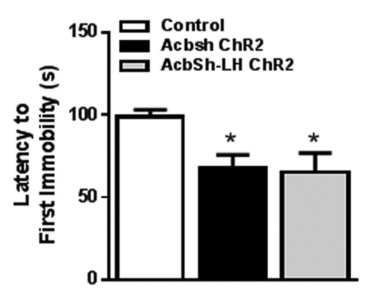

B

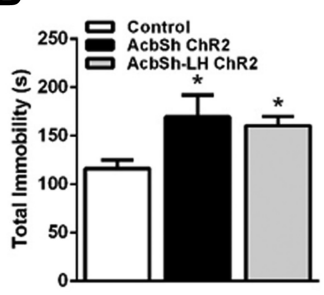

C

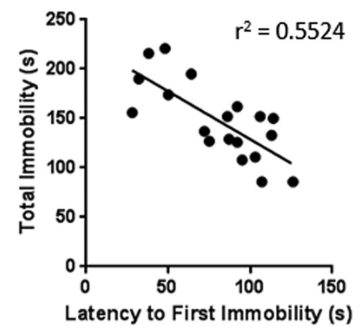

D

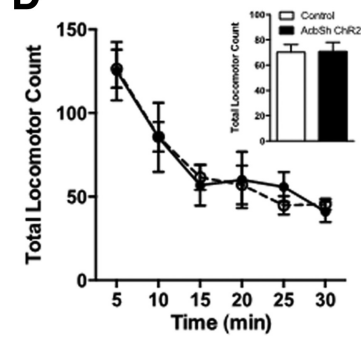

Figure 3. Optogenetic stimulation of either global AcbSh neurons or selective AcbSh-LH terminals facilitates depressive-like behavioral despair. $\boldsymbol{A}$, Optogenetic stimulation reduced the latency to first immobility and $(\boldsymbol{B})$ increased the total time spent immobile during forced swim testing $(\boldsymbol{C})$. All animals showed a negative correlation between latency and total immobility measures. $\boldsymbol{D}$, There was no effect of global AcbSh neuron stimulation on general locomotor activity; $n=4-9 /$ group.

$E, F)$. It should be noted that cannulae in more anterior portions of the LH in a few animals (e.g., -1.80 relative to bregma) were $>0.5 \mathrm{~mm}$ caudal to the lateral preoptic area and posterior VP. Thus, it is unlikely that these areas could account for the behavioral effects of AcbSh-LH terminal stimulation.

\section{Differential effects of AcbSh neuron and AcbSh-LH terminal stimulation on cocaine self-administration and extinction} The effects of optogenetic stimulation of either global AcbSh neurons or selective AcbSh-LH terminals were examined in animals that had self-administered cocaine for 3 weeks (Fig. 2). There were no group differences in self-administration behavior before optogenetic stimulation, and no differences in cocaine intake between EYFP controls with either AcbSh or LH optical cannula (Fig. 2A). Thus, data from the control groups were combined for subsequent analyses. During PR testing, optogenetic treatment altered the breakpoints for cessation of cocaine selfadministration (group effect: $F_{(2,26)}=4.312, p<0.05$ ). Global AcbSh stimulation tended to reduce responding for cocaine on Day 1 of testing; however, this trend failed to reach statistical significance compared with controls in post hoc tests. In contrast, AcbSh-LH stimulated animals reached significantly higher breakpoints on Day 2 of PR testing compared with controls, contributing to a significant effect of test day $\left(F_{(1,26)}=21.56, p<\right.$ $0.0001)$ along with a trend for interaction between these variables $\left(F_{(2,26)}=2.453, p=0.10\right)$. Group differences in breakpoints appear to be a direct reflection of the motivation to selfadminister cocaine, as all groups had similar response rates at low response/injection ratios earlier in the session (data not shown).

In addition to the direct effects of optogenetic stimulation on cocaine self-administration, we examined the potential for longterm effects by re-exposing animals to the self-administration context under extinction conditions after 1 week of withdrawal from cocaine self-administration (Fig. 2C). Prior optogenetic treatment significantly altered responses at the drug-paired lever during extinction testing (group $\times$ test day interaction effect: $\left.F_{(10,130)}=2.341, p=0.014\right)$, although all groups extinguished responding to similar levels over the course of testing (day effect: $\left.F_{(5,130)}=30.92, p<0.0001\right)$. Post hoc analysis indicated that animals with prior optogenetic stimulation of AcbSh-LH terminals exhibited higher cocaine-seeking behavior on Day 1 of extinction testing compared with EYFP controls. Conversely, animals receiving prior global AcbSh stimulation tended to show reduced cocaine-seeking on Day 1 . A closer look at Day 1 of extinction (Fig. 2D) confirmed differences in responding due to prior optogenetic treatment (group effect: $F_{(2,26)}=4.286, p=$ 0.025 ), and post hoc comparisons here revealed significant reductions in cocaine-seeking in animals with prior AcbSh stimulation during the first hour of testing. Thus, prior optogenetic treatment of AcbSh neurons or selective treatment of AcbSh-LH terminals produces opposing and enduring effects on cocaine-seeking behavior in the absence of cocaine reinforcement.

\section{Optogenetic stimulation of either AcbSh or AcbSh-LH neurons promotes behavioral despair}

Because altered activity in AcbSh and LH neurons has been implicated in stress-related aversive and/or negative affective mood states, we also tested whether the same optogenetic stimulation parameters would alter depression-like behavior in the forced swim test (Fig. 3). In stark contrast to the differential effects on cocaine self-administration and extinction, we found that optogenetic stimulation of either global AcbSh neurons or selective AcbSh-LH terminals resulted in similar prodepressive effects in this test. Thus, the 30 min optogenetic treatment produced a significant decrease in the latency to immobility (Fig. $3 A$; group effect: $\left.F_{(2,19)}=4.724, p=0.0216\right)$, and increased total immobility time (Fig. $3 B$; group effect: $F_{(2,19)}=6.313, p=0.0079$ ). In general, there was a significant negative correlation between immobility measures $(r=0.7432, p=0.0003)$; animals that became immobile faster also stayed immobile for longer, and this occurred regardless of the treatment condition (Fig. 3C). Notably, neither immobility in the forced swim test nor reduced operant behavior following global AcbSh stimulation was related to motor deficits or overall behavioral suppression, as this stimulation produced no decrement in novelty-induced locomotor activity (Fig. 3D).

\section{Optogenetic stimulation of AcbSh neurons and downstream modulation of neuronal activity in the $\mathrm{LH}$}

To determine whether AcbSh neurons are capable of responding to the optogenetic stimulation parameters that were used for in vivo treatments, we performed whole-cell patch-clamp recordings in acute slices of AcbSh 4-5 weeks after rats received AAVChR2-EYFP infusions in the AcbSh. EYFP-expressing neurons in the AcbSh were identified as medium spiny projection neurons by their membrane properties and response to current injection (Fig. 4A). Direct optogenetic stimulation of recorded neurons elicited action potential bursts in response to $20 \mathrm{~Hz}$ light pulses with minimal accommodation (Fig. $4 B$ ), even when the 10 s pulse trains were presented at $30 \mathrm{~s}$ intervals (twice the rate of in vivo stimulation). Moreover, action potentials within each burst were time-locked to the $10 \mathrm{~ms}$ light pulses, indicating that AcbSh projection neurons can respond reliably to $20 \mathrm{~Hz}$ stimulation. In the $\mathrm{LH}$, we recorded from neurons surrounded by EYFP + terminals from the AcbSh that are thought to primarily release GABA (Fig. 4C). In this case, the light pulses elicited IPSCs (IPSCs) (Fig. 4D) 
A

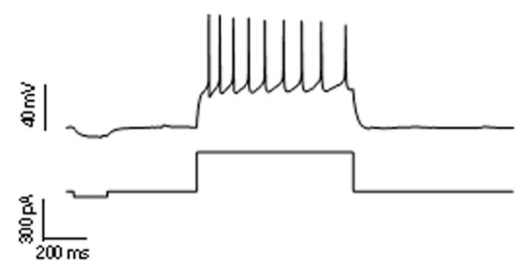

B

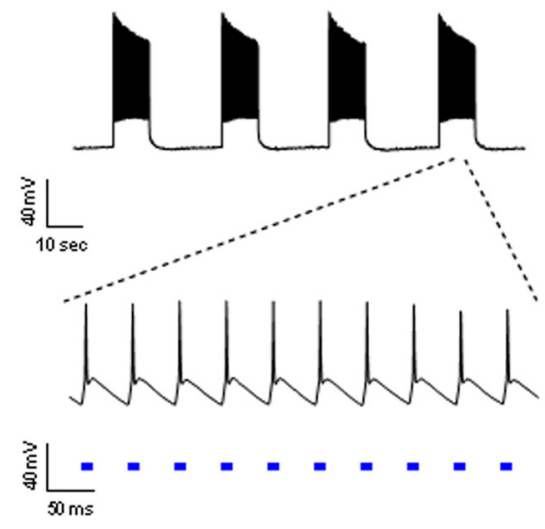

C

$\mathrm{LH}$

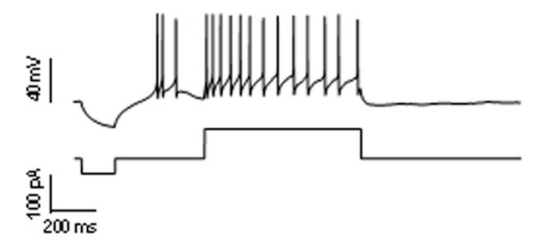

D

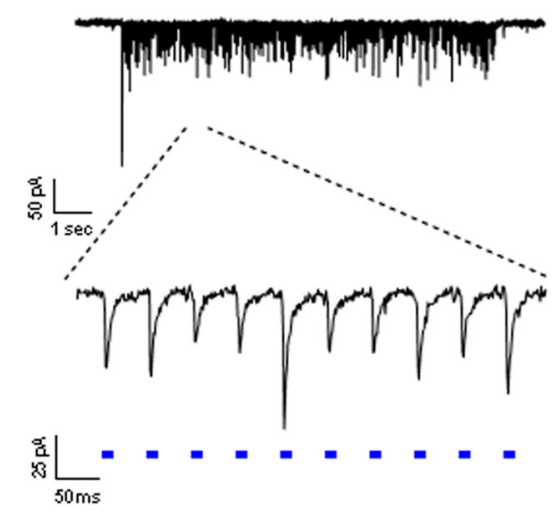

Figure 4. In vitro validation of stimulation parameters. The stimulation paradigm used for in vivo experiments was tested in slices of the $\operatorname{AcbSh}(\boldsymbol{A}, \boldsymbol{B})$ and $\mathrm{LH}(\boldsymbol{C}, \boldsymbol{D}) . \boldsymbol{A}, \mathrm{EYFP}+$ neuron in an AcbSh slice recorded in current-clamp; current step delivery confirms neuron health and medium spiny neuron identity. $\boldsymbol{B}, 0$ ptogenetic stimulation of the neuron in $\boldsymbol{A}$ produces reliable action potential firing with the in vivo $10 \mathrm{~s} 20 \mathrm{~Hz}$ burst paradigm, repeated every $30 \mathrm{~s}$ for $10 \mathrm{~min}$ to confirm response stability. $C$, LH neuron recorded in a slice containing dense EYFP terminal labeling responds to current step delivery. $\boldsymbol{D}$, Voltage-clamp recording of the neuron in $\boldsymbol{C}$ showing inward IPSCs in response to optogenetic AcbSh-LH terminal stimulation for $10 \mathrm{~s}$ at $20 \mathrm{~Hz}$ in the presence of kynurenic acid.

that were blocked by the GABA receptor antagonist picrotoxin (data not shown). LH neuronal responses to AcbSh-LH terminal stimulation also tracked with the $20 \mathrm{~Hz}$ stimulus train. These results indicate that both AcbSh cell bodies and postsynaptic LH neurons respond reliably to the optogenetic stimulation parameters used in vivo.

To complement physiological assessment in vitro, we measured cFos immunoreactivity after optogenetic stimulation in vivo following the forced swim tests (Fig. 5). Optogenetic treatment significantly altered cFos immunoreactivity in the AcbSh (group effect: $F_{(2,18)}=8.535, p=0.0025$ ) and the LH (group effect: $\left.F_{(2,19)}=6.522, p=0.0070\right)$. Post hoc tests revealed that optogenetic stimulation of AcbSh cell bodies induced cFos locally in AcbSh neurons, leading to a doubling of cFos + neurons compared with EYFP controls (Fig. 5A, top left, $B$ ). In contrast, stimulation of AcbSh-LH terminals had no effect on cFos in the AcbSh (Fig. 5A, bottom left, $B$ ), consistent with a lack of antidromic stimulation. However, stimulation of either AcbSh cell bodies or AcbSh-LH terminals decreased cFos-immunoreactive neurons in the LH by $\sim 50 \%$ (Fig. $5 A$ rights, $C$ ), consistent with activation of inhibitory GABArergic projections to the $\mathrm{LH}$ in both cases. Interestingly, stimulation-related reductions in cFos in the LH appeared to occur mainly in orexin + neurons. Optogenetic treatment significantly altered cFos immunoreactivity in orexin + neurons (group effect: $F_{(2,15)}=8.020, p=0.0043$ ), and post hoc comparisons confirmed a significant $\sim 50 \%$ reduction in orexin/cFos colocalization in response to optogenetic stimulation of global AcbSh neurons or selective AcbSh-LH terminals. Therefore, it is possible that decreases in orexin neuron activity may have contributed to the behavioral effects of optogenetic stimulation.

\section{Discussion}

The findings of the present study clearly show that optogenetic activation of AcbSh and AcbSh-LH neurons produces differential effects on addictive behavior reinforced by intravenous cocaine injections. Using animals with a history of volitional cocaine self-administration, we found that selective stimulation of AcbSh-LH terminals strongly enhanced the motivation for cocaine and led to long-lasting facilitation of cocaine-seeking behavior after withdrawal. These data are consistent with previous studies showing that contextinduced reinstatement of alcohol-seeking behavior is associated with activation of AcbSh-LH outputs (Marchant et al., 2009), and also indicate that activation of AcbSh-LH outputs may be important for directing drug-seeking behavior across drug classes. In contrast to selective AcbSh-LH stimulation, we found that nondiscriminate stimulation of AcbSh neurons produced only marginal reductions in the motivation for cocaine during self-administration, yet led to a long-lasting attenuation of cocaineseeking after withdrawal from cocaine self-administration. The overall tendency for inhibitory behavioral effects in response to AcbSh stimulation complements previous studies showing that pharmacological inhibition of the AcbSh facilitates food intake (Stratford and Kelley, 1999; Reynolds and Berridge, 2001) and reinstates extinguished drug-seeking behavior (Peters et al., 2008; Millan et al., 2010). Together, these data suggest that the AcbSh-LH projection plays an important role in modulating drug-directed behavior that is distinct from that played by other populations of AcbSh neurons.

Given that CREB activity in the AcbSh facilitates motivation for cocaine (Larson et al., 2011), promotes depression-like behavior (Pliakas et al., 2001), and enhances excitability of AcbSh neurons (Dong et al., 2006), we initially hypothesized that AcbSh activity would induce a depressed behavioral state, which enhances the motivation for cocaine through negative reinforcement processes that alleviate such depression. Indeed, we found that both global stimulation of AcbSh neurons and selective stimulation of AcbSh-LH terminals induce depression-like behavior in the forced swim test. Although our results support the hypothesis that elevated AcbSh activity would promote negative affective states, the finding that global stimulation of AcbSh neurons failed to enhance the motivation for cocaine and led to reduced cocaine-seeking under extinction conditions indicates that such behavioral despair may not directly contribute to negative reinforcement processes in cocaine addiction. At the same time, global AcbSh neuron stimulation presumably activates all three major AcbSh outputs (to the VTA, VP, and LH), and each output would likely contribute to behavioral responses to overall AcbSh stimulation. Therefore, an alternative possibility is that the AcbSh-LH pathway itself does contribute to negative reinforcement processes, but these effects are masked by the dominant 
A
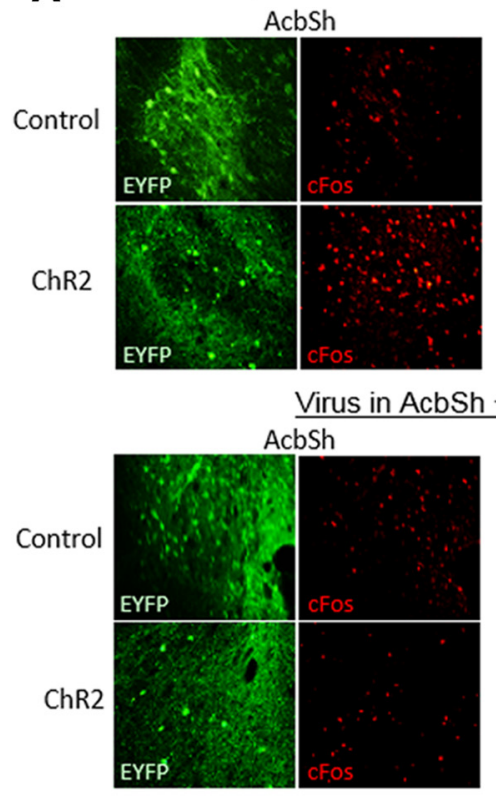

Virus in AcbSh + Optic Implant in LH

Virus in AcbSh + Optic Implant in AcbSh

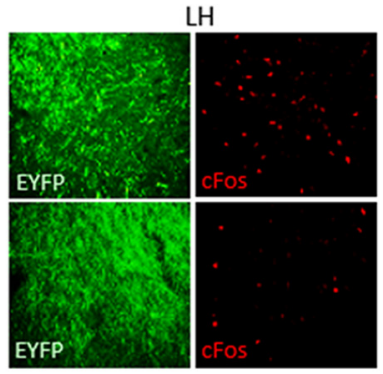

$\mathrm{LH}$

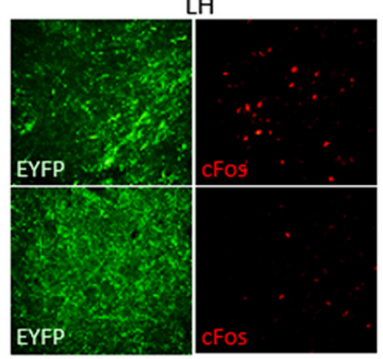

B

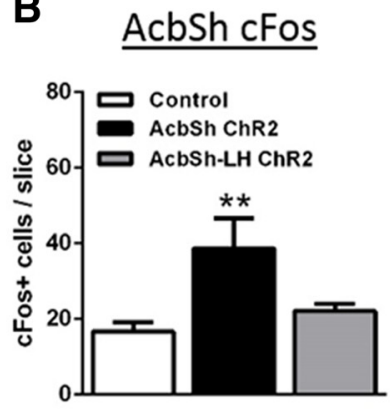

D

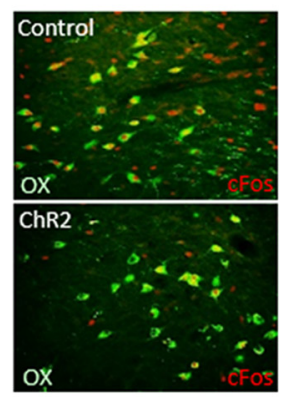

C

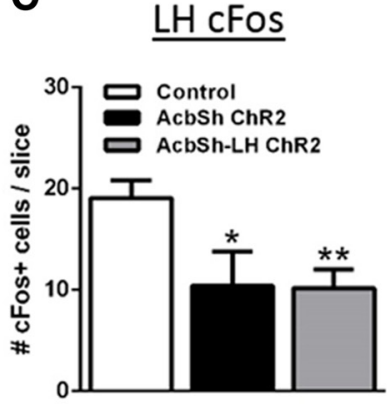

E $\underline{\text { LH OX/CFOS }}$

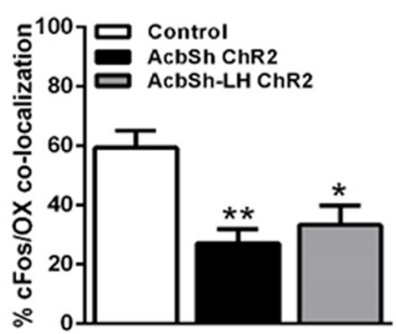

Figure 5. Optogenetic stimulation of either global AcbSh neurons or selective AcbSh-LH terminals reduces cFos in LH orexin neurons. $A$, Representative images $(40 \mu \mathrm{m}, 20 \times)$ of EYFP (green) and CFos (red) immunoreactivity in the AcbSh and LH 90 min after optogenetic stimulation and FST behavioral testing in global AcbSh (top) and selective AcbSh-LH (bottom) stimulated groups. $\boldsymbol{B}$, AcbSh cFos was elevated only after global AcbSh stimulation. C, LH cFos was reduced after either global AcbSh or selective AcbSh-LH terminal stimulation. $\boldsymbol{D}$, Representative images showing reductions in CFos (red)/orexin (OX; green) colocalization after optogenetic stimulation. $E$, cFos/OX colocalization was reduced by either global AcbSh neuron or selective AcbSh-LH terminal stimulation; ${ }^{*} p<$ $0.05,{ }^{* *} p<0.01$ versus control; $n=4-9 /$ group.

influence of non-LH AcbSh outputs that reduce the motivation for cocaine through different mechanisms. Interestingly, global AcbSh stimulation has the potential to stimulate a large population of D1-expressing AcbSh-VTA neurons (Lu et al., 1998), which could reduce cocaine-seeking through activation of primary reward processes and the satiation of cocaine craving. This intriguing possibility is supported by the fact that optogenetic stimulation of D1-expressing AcbSh cell bodies can facilitate cocaineconditioned place preference (Lobo et al., 2010), and that global activation of AcbSh neurons may be rewarding unto itself (Britt et al., 2012).

It is important to note that the reduction in motivation for cocaine after global AcbSh stimulation was less direct than the enhanced motivation induced by AcbSh-LH terminal stimulation, as minor reductions in breakpoints for cocaine selfadministration were not statistically different from controls. However, it is possible that the competing promotivational influence of the AcbSh-LH output weakened the influence of other non-LH AcbSh outputs that reduce the motivation for cocaine. Thus, selective stimulation of non-LH AcbSh outputs could reveal more pronounced circuit-specific decrements in the motivation for cocaine. Differential and potentially opposing influences of LH and non-LH AcbSh output neurons on addictive behavior is consistent with recent findings on the role of cell-specific amygdala outputs in anxiety-like behavior (Tye et al., 2011), and illustrate the power of optogenetics to elucidate circuit-specific differences in behavioral valence emanating from a common brain nucleus.

The opposing influences of global AcbSh and AcbSh-LH terminal stimulation on the motivation for cocaine are intriguing given that both stimulation protocols produced evidence of reduced neuronal activity in the LH, including prominent reductions in cFos in orexin $+\mathrm{LH}$ neurons. These findings support work indicating that the AcbSh provides an inhibitory influence on LH orexin neurons (Stratford and Kelley, 1999; Zheng et al., 2003; Millan et al., 2010), and are consistent with studies suggesting that low orexin levels are associated with depression (Nocjar et al., 2012). However, they contrast with studies suggesting that motivation for cocaine involves increased rather that decreased activity in orexin neurons (Aston-Jones et al., 2010; Sharf et al., 2010). The ability of AcbSh and AcbSh-LH stimulation to reduce cFos in LH orexin neurons may relate to the stressful nature of the forced swim test that normally activates these neurons. The orexin neurons that exert positive influence on the motivation for cocaine (e.g., those projecting to the VTA) may also differ from the orexin neurons inhibited by our AcbSh stimulation protocols. Alternatively, AcbSh-LH terminal stimulation may augment the salience of environmental stimuli, whether aversive like swim stress or appetitive like cocaine. In addition, AcbSh neurons may display motivation-related responses to appetitive stimuli that are distinct from their responses to the emotional/affective aspects of these same stimuli (Richard et al., 2013). Finally, AcbSh activity may mediate motivational responses that are entirely retuned by environmental stimuli (Reynolds and Berridge, 2008).

Overall, our findings demonstrate that activation of AcbSh neurons can directly modulate the behavioral responses to both rewarding (cocaine) and aversive (stress) stimuli. The dissociable effects of AcbSh and AcbSh-LH stimulation on addictive and depressive behavior indicate that distinct yet overlapping circuits emanating from the AcbSh can independently modulate both motivation and mood, and that each individual AcbSh output may provide unique influences depending on the nature of the stimulus. Importantly, the findings provide direct evidence that AcbSh-LH neurons play a key and perhaps distinct role in mediating the motivation for cocaine and depressive-like behavioral despair. The ability of this AcbSh-LH output to promote both addictive and depressive behavior suggests that inhibition of this output may be beneficial for the treatment of these disorders. In 
contrast, global stimulation of AcbSh neurons is likely a less effective approach, as it may depress mood in addition to beneficial inhibition of drug-seeking behavior. Ultimately, it will be important to examine each Acb output emanating from distinct core and shell subregions with respect to both drug- and stress-related stimuli to fully appreciate the complexity of behavioral repertoires regulated by this brain region.

\section{References}

Adamantidis AR, Zhang F, Aravanis AM, Deisseroth K, de Lecea L (2007) Neural substrates of awakening probed with optogenetic control of hypocretin neurons. Nature 450:420-424. CrossRef Medline

Aston-Jones G, Smith RJ, Sartor GC, Moorman DE, Massi L, Tahsili-Fahadan P, Richardson KA (2010) Lateral hypothalamic orexin/hypocretin neurons: a role in reward-seeking and addiction. Brain Res 1314:74-90. CrossRef Medline

Belleau ML, Warren RA (2000) Postnatal development of electrophysiological properties of nucleus accumbens neurons. J Neurophysiol 84:22042216. Medline

Berridge CW, España RA, Vittoz NM (2010) Hypocretin/orexin in arousal and stress. Brain Res 1314:91-102. CrossRef Medline

Berridge KC, Kringelbach ML (2013) Neuroscience of affect: brain mechanisms of pleasure and displeasure. Curr Opin Neurobiol 23:294-303. CrossRef Medline

Britt JP, Benaliouad F, McDevitt RA, Stuber GD, Wise RA, Bonci A (2012) Synaptic and behavioral profile of multiple glutamatergic inputs to the nucleus accumbens. Neuron 76:790-803. CrossRef Medline

Carlezon WA Jr, Thomas MJ (2009) Biological substrates of reward and aversion: a nucleus accumbens activity hypothesis. Neuropharmacology 56:122-132. CrossRef Medline

Castagné V, Moser P, Roux S, Porsolt RD (2011) Rodent models of depression: forced swim and tail suspension behavioral despair tests in rats and mice. Curr Protoc Neurosci 8:8.10A. CrossRef Medline

Dong Y, Green T, Saal D, Marie H, Neve R, Nestler EJ, Malenka RC (2006) CREB modulates excitability of nucleus accumbens neurons. Nat Neurosci 9:475-477. CrossRef Medline

Edwards S, Whisler KN, Fuller DC, Orsulak PJ, Self DW (2007) Addictionrelated alterations in D1 and D2 dopamine receptor behavioral responses following chronic cocaine self-administration. Neuropsychopharmacology 32:354-366. CrossRef Medline

Eshel N, Roiser JP (2010) Reward and punishment processing in depression. Biol Psychiatry 68:118-124. CrossRef Medline

Frankowska M, Gołda A, Wydra K, Gruca P, Papp M, Filip M (2010) Effects of imipramine or GABA(B) receptor ligands on the immobility, swimming and climbing in the forced swim test in rats following discontinuation of cocaine self-administration. Eur J Pharmacol 627:142-149. CrossRef Medline

Kelley AE, Baldo BA, Pratt WE, Will MJ (2005) Corticostriatal-hypothalamic circuitry and food motivation: integration of energy, action and reward. Physiol Behav 86:773-795. CrossRef Medline

Kravitz AV, Kreitzer AC (2012) Striatal mechanisms underlying movement, reinforcement, and punishment. Physiology 27:167-177. CrossRef Medline

Larson EB, Graham DL, Arzaga RR, Buzin N, Webb J, Green TA, Bass CE, Neve RL, Terwilliger EF, Nestler EJ, Self DW (2011) Overexpression of CREB in the nucleus accumbens shell increases cocaine reinforcement in self-administering rats. J Neurosci 31:16447-16457. CrossRef Medline

Lobo MK, Covington HE 3rd, Chaudhury D, Friedman AK, Sun H, DamezWerno D, Dietz DM, Zaman S, Koo JW, Kennedy PJ, Mouzon E, Mogri M, Neve RL, Deisseroth K, Han MH, Nestler EJ (2010) Cell type-specific loss of BDNF signaling mimics optogenetic control of cocaine reward. Science 330:385-390. CrossRef Medline

Lu XY, Ghasemzadeh MB, Kalivas PW (1998) Expression of $\mathrm{D}_{1}$ receptor, $\mathrm{D}_{2}$ receptor, substance $\mathrm{P}$ and enkephalin messenger RNAs in the neurons projecting from the nucleus accumbens. Neuroscience 82:767-780. CrossRef Medline

Marchant NJ, Hamlin AS, McNally GP (2009) Lateral hypothalamus is re- quired for context-induced reinstatement of extinguished reward seeking. J Neurosci 29:1331-1342. CrossRef Medline

Marchant NJ, Millan EZ, McNally GP (2012) The hypothalamus and the neurobiology of drug seeking. Cell Molec Life Sci 69:581-597. CrossRef Medline

Markou A, Koob GF (1991) Postcocaine anhedonia: an animal model of cocaine withdrawal. Neuropsychopharmacology 4:17-26. Medline

Martinez M, Phillips PJ, Herbert J (1998) Adaptation in patterns of c-fos expression in the brain associated with exposure to either single or repeated social stress in male rats. Eur J Neurosci 10:20-33. CrossRef Medline

Millan EZ, Furlong TM, McNally GP (2010) Accumbens shell-hypothalamus interactions mediate extinction of alcohol seeking. J Neurosci 30:4626-4635. CrossRef Medline

Morgan JI, Curran T (1989) Stimulus-transcription coupling in neurons: role of cellular immediate-early genes. Trends Neurosci 12:459-462. CrossRef Medline

Muschamp JW, Van't Veer A, Parsegian A, Gallo MS, Chen M, Neve RL, Meloni EG, Carlezon WA Jr (2011) Activation of CREB in the nucleus accumbens shell produces anhedonia and resistance to extinction of fear in rats. J Neurosci 31:3095-3103. CrossRef Medline

Nocjar C, Zhang J, Feng P, Panksepp J (2012) The social defeat animal model of depression shows diminished levels of orexin in mesocortical regions of the dopamine system, and of dynorphin and orexin in the hypothalamus. Neuroscience 218:138-153. CrossRef Medline

Paxinos G, Watson GC (1998) The rat brain in stereotaxic coordinates, Ed 4. New York: Academic

Peters J, LaLumiere RT, Kalivas PW (2008) Infralimbic prefrontal cortex is responsible for inhibiting cocaine seeking in extinguished rats. J Neurosci 28:6046-6053. CrossRef Medline

Pliakas AM, Carlson RR, Neve RL, Konradi C, Nestler EJ, Carlezon WA Jr (2001) Altered responsiveness to cocaine and increased immobility in the forced swim test associated with elevated cAMP response elementbinding protein expression in nucleus accumbens. J Neurosci 21:73977403. Medline

Reynolds SM, Berridge KC (2001) Fear and feeding in the nucleus accumbens shell: rostrocaudal segregation of GABA-elicited defensive behavior versus eating behavior. J Neurosci 21:3261-3270. Medline

Reynolds SM, Berridge KC (2008) Emotional environments retune the valence of appetitive versus fearful functions in nucleus accumbens. Nat Neurosci 11:423-425. CrossRef Medline

Richard JM, Plawecki AM, Berridge KC (2013) Nucleus accumbens GABAergic inhibition generates intense eating and fear that resists environmental retuning and needs no local dopamine. Eur J Neurosci 37: 1789-1802. CrossRef Medline

Richardson NR, Roberts DC (1996) Progressive ratio schedules in drug selfadministration studies in rats: a method to evaluate reinforcing efficacy. J Neurosci Methods 66:1-11. CrossRef Medline

Sano H, Yokoi M (2007) Striatal medium spiny neurons terminate in a distinct region in the lateral hypothalamic area and do not directly innervate orexin/hypocretin- or melanin-concentrating hormone-containing neurons. J Neurosci 27:6948-6955. CrossRef Medline

Self DW, Nestler EJ (1998) Relapse to drug-seeking: neural and molecular mechanisms. Drug Alcohol Depend 51:49-60. CrossRef Medline

Sharf R, Sarhan M, Dileone RJ (2010) Role of orexin/hypocretin in dependence and addiction. Brain Res 1314:130-138. CrossRef Medline

Stratford TR, Kelley AE (1999) Evidence of a functional relationship between the nucleus accumbens shell and lateral hypothalamus subserving the control of feeding behavior. J Neurosci 19:11040-11048. Medline

Tye KM, Prakash R, Kim SY, Fenno LE, Grosenick L, Zarabi H, Thompson KR, Gradinaru V, Ramakrishnan C, Deisseroth K (2011) Amygdala circuitry mediating reversible and bidirectional control of anxiety. Nature 471:358-362. CrossRef Medline

Zheng H, Corkern M, Stoyanova I, Patterson LM, Tian R, Berthoud HR (2003) Peptides that regulate food intake: appetite-inducing accumbens manipulation activates hypothalamic orexin neurons and inhibits POMC neurons. Am J Physiol Regul Integr Comp Physiol 284:R1436-R1444. CrossRef Medline 